\title{
Surgeon-administered ilioinguinal and pudendal nerve blocks for vulval oncology surgery: An observational evaluation study with Visual Analogue Pain Scoring Shahabuddin Y., Gleeson N., Maguire PJ. Department of Gynaecological Oncology, St James's Hospital, Dublin 8, Ireland.
}

\author{
Yulia Shahabuddin ${ }^{1}$, Noreen Gleeson ${ }^{2}$, and Patrick Maguire ${ }^{3}$ \\ ${ }^{1}$ St James's Hospital \\ ${ }^{2}$ Trinity College Dublin \\ ${ }^{3}$ Affiliation not available
}

November 13, 2020

\begin{abstract}
Objective To assess pain scores and requirement for parenteral and oral analgesia in the postoperative period following vulval surgery with blockade of the ilioinguinal nerve (IIN) and pudendal nerve (PN). Design An observational study of consecutive patients undergoing major vulval and/or related groin surgery. Sampling biopsies were excluded. Setting Women undergoing vulval surgery in a tertiary cancer centre. Population or Sample Eighteen women were included in the analysis. Median age 67 (range 34-81) years and thirteen $(72 \%)$ were $>60$ years. Methods Levobupivacaine $0.25 \%(2.5 \mathrm{mg} / \mathrm{ml})$ or $0.5 \%(5 \mathrm{mg} / \mathrm{ml})$ was administered at four sites (2 sites abdominally for IIN block and 2 sites for PN block) with dosage calculated based on the patient's weight. Patients were invited to record visual analogue pain scores (VAS) days 1-5 postoperatively. Use of postoperative analgesia was recorded. Main Outcome Measures VAS and use of postoperative analgesia. Results VAS ranged from 0 to 3 for seventeen patients from day 0 to day 1 and fifteen patients from day 2 to day 5 . Two patients had pain scores $>4$ on one or more postoperative days: one had chronic arthralgia and one had received a lower volume of bupivacaine. Conclusions Ilio-inguinal and pudendal nerve block is a feasible and effective strategy for postoperative pain management in women undergoing vulval surgery.
\end{abstract}

\section{Hosted file}

Final_BJOG_submission_for_Ilioinguinal_study- First correction 12th Nov 2020.pdf available at https://authorea.com/users/375608/articles/492772-surgeon-administered-ilioinguinaland-pudendal-nerve-blocks-for-vulval-oncology-surgery-an-observational-evaluation-studywith-visual-analogue-pain-scoring-shahabuddin-y-gleeson-n-maguire-pj-department-ofgynaecological-oncology-st-james-s-hospital-dublin-8-ireland

\section{Hosted file}

Figure 1.pdf available at https://authorea.com/users/375608/articles/492772-surgeonadministered-ilioinguinal-and-pudendal-nerve-blocks-for-vulval-oncology-surgery-anobservational-evaluation-study-with-visual-analogue-pain-scoring-shahabuddin-y-gleesonn-maguire-pj-department-of-gynaecological-oncology-st-james-s-hospital-dublin-8-ireland

\section{Hosted file}


Figure 2.pdf available at https://authorea.com/users/375608/articles/492772-surgeonadministered-ilioinguinal-and-pudendal-nerve-blocks-for-vulval-oncology-surgery-anobservational-evaluation-study-with-visual-analogue-pain-scoring-shahabuddin-y-gleesonn-maguire-pj-department-of-gynaecological-oncology-st-james-s-hospital-dublin-8-ireland

\section{Hosted file}

Figure 3.pdf available at https://authorea.com/users/375608/articles/492772-surgeonadministered-ilioinguinal-and-pudendal-nerve-blocks-for-vulval-oncology-surgery-anobservational-evaluation-study-with-visual-analogue-pain-scoring-shahabuddin-y-gleesonn-maguire-pj-department-of-gynaecological-oncology-st-james-s-hospital-dublin-8-ireland

\section{Hosted file}

Figure 4.pdf available at https://authorea.com/users/375608/articles/492772-surgeonadministered-ilioinguinal-and-pudendal-nerve-blocks-for-vulval-oncology-surgery-anobservational-evaluation-study-with-visual-analogue-pain-scoring-shahabuddin-y-gleesonn-maguire-pj-department-of-gynaecological-oncology-st-james-s-hospital-dublin-8-ireland 